\title{
Acknowledgments
}

This book owes a lot to an informal seminar that was held twice a day for thirty to forty minutes over more than two years as Jay Haley, Braulio Montalvo, and I were driving to and from the Philadelphia Child Guidance Clinic. Many of the ideas presented here emerged from our discussions, for which I am deeply grateful. I especially thank Braulio Montalvo, whom I consider my most influential teacher. He has the rare capacity to receive an idea and then give it back enlarged. At many times during our ten years of working together he has redirected my thinking, and has always enriched it. I have also benefited from the assistance of Frances Hitchcock, who for seven years helped me to clarify my ideas and to turn them into prose.

Many of my colleagues at the Philadelphia Child Guidance Clinic made contributions to this book, bouncing ideas back and forth with me. I especially want to mention the faculty of the Institute of Family Counseling, and in particular, Jerome Ford, Carter Umbarger, Marianne Walters, and Rae Weiner.

This book began as a series of lectures presented to groups in the United States, Sweden, and Holland. I wish to thank my students of the Group Psychotherapy Association in Holland, who contributed examples and shared their views. Mordecai Kaffman, M.D., kindly interviewed the Israeli family especially for this book. Finally, thanks are due to Lyman Wynne for his helpful suggestions in reviewing the manuscript and to Virginia LaPlante for her work in editing the book. 


\section{A NOTE ON THE TRANSCRIPTS}

The transcripts in this book have been edited to protect the privacy of the families interviewed. When necessary, meanings have been clarified.

Before the presentation of the transcripts, references are sometimes made to the families involved, as examples of various points. This anticipatory device is used to familiarize the reader with the cases, so that when he reaches the full account of each session, he need give less attention to content and more to the therapeutic process.

The Smith, Dodds, and Gorden family interviews have been made into movies, with analysis provided by Braulio Montalvo. They are titled "I Think It's Me-Difference Display As a Contextual Event" (Chapter 9), "Affinity" (Chapter 10), and "A Family with a Little Fire" (Chapter 11). Information on these films is available from the Philadelphia Child Guidance Clinic, 1700 Bainbridge Street, Philadelphia, Pennsylvania 19146.

Salvador Minuchin, M.D. 